\title{
Introduction: new trends in the metaphysics of science
}

\author{
Max Kistler $^{1}$ (D)
}

Published online: 24 May 2018

(C) Springer Science+Business Media B.V., part of Springer Nature 2018

At the beginning of the twentieth century, philosophy of science defined itself mainly in opposition to metaphysics (Mach 1883; Duhem 1906; Carnap 1931), which was taken to be a field lacking rigorous methods, thus being hostage to arbitrariness and dogmatism (Hahn et al. 1929). Logical empiricism, first promoted in Vienna and Berlin in the 1920s and the beginning of the 1930s, recommended abandoning metaphysical theories with their shaky epistemic status and suggested a new start based on the hypothesis of the unity of science (Hahn et al. 1929). According to logical empiricism, scientific knowledge is better justified than metaphysics because it rests on a solid foundation: the pillars of observation and logic. Metaphysical statements, which cannot be justified by observation or logic, were taken to be strictly speaking meaningless. Given this conception of metaphysics and science that has been dominant in much of the twentieth century, it may seem surprising, and even paradoxical, to open up a new field of research under the name of "metaphysics of science" or "scientific metaphysics", with the aim of pursuing metaphysical questions in the light of contemporary science or of interpreting contemporary science in metaphysical terms. How can it be legitimate to raise questions about the structure of reality revealed by the sciences in metaphysical terms?

According to the doctrine of logical empiricism, metaphysical questions that arise about the objects of scientific research can only be addressed in a rational and coherent way once they have been translated into questions bearing on scientific theories, con-

Max Kistler

mkistler@univ-paris1.fr

http://max.kistler.free.fr

1 IHPST (Institut d'histoire et de philosophie des sciences et des techniques), Université Paris 1 Panthéon-Sorbonne, CNRS, 13 rue du Four, 75006 Paris, France 
strued as sets of propositions. To the question of what is meant by the statement that a physical or biological event causes another event, logical empiricism substituted the analysis of the logical form of causal explanations provided by the sciences (Hempel and Oppenheim 1948). To the question: "what is a dispositional property?" (such as elasticity or electrical conductivity in physics, reactivity in chemistry, or fitness in biology), it substituted the analysis of the logical form of disposition statements (Carnap 1936, 1937). In this conception, there is no room for metaphysical questions as such; metaphysics is seen at best as a conceptual framework that makes scientific research possible but has itself the status of a convention (Carnap 1950).

However, during the second half of the twentieth century it turned out that the distinctions that helped to justify the neat separation between science and metaphysics, that is, between the empirical content and the conventional form of scientific propositions, were themselves ill grounded. There is no difference in principle but only in degree between analytic and synthetic statements (Quine 1953/1980b); furthermore, it has become controversial whether there is a principled distinction between observational and theoretical statements, which might ground a metaphysical distinction between "observable" and "theoretical" entities (Maxwell 1962; Kuhn 1962; Hacking 1983).

This evolution explains why it has become legitimate again to address metaphysical issues on a background of contemporary science. It now appears artificial to separate the analysis of the general conceptual tools that are used throughout the sciences, such as cause, law, individual object, process, mechanism, reduction, from the metaphysical analysis of the structure of reality as represented by science.

The earliest form this "return to metaphysics" has taken is the conception of ontology developed by Quine (1953/1980a): the ontology of a given (scientific or popular) theory consists of the objects to which the theory is "ontologically committed", that is, the objects that exist if the theory is correct. Technically, Quine's proposal is to take quantification as a criterion of ontological commitment. His hypothesis is that a theory is committed to the existence of a set of objects if and only if they belong to the domain in which the bound variables appearing in the axioms and theorems of the theory take their values. More simply, the idea is to look at the universal ("every object $\mathrm{x}$ is such that...") and existential ("there is an object $x$ such that...") generalizations that are part of the theory. What exists according to the theory is the set of objects in which the variables x take their values. However, Quine's conception cannot be adequately used when many formal versions of the same theory exist (e.g., in classical mechanics) or when many interpretations of the theory are sustainable (e.g., in quantum mechanics). Moreover, metaphysics is wider than ontology; if the aim of ontology is to enquire into the fundamental kinds of entities that exist, metaphysics also explores concepts expressing the structure, dynamics and interaction of these entities, such as the concepts of law, causation, necessity and possibility, and reduction and emergence. In metaphysics of science, both questions - what exists? And how do the entities that exist evolve and interact? - are addressed on the background of contemporary science.

Today, the field of metaphysics of science is blossoming. Unsurprisingly for such a fundamental branch of philosophy as metaphysics, the scope, aims and methods, and even the very possibility of the discipline remain controversial. The common 
denominator of all work lying within this new domain is to pursue metaphysics in the light of contemporary scientific knowledge.

The articles collected in this special issue were presented at a workshop on New Trends in the Metaphysics of Science, organized by IHPST (Institute for the History and Philosophy of Science and Technology), University of Paris 1, Panthéon-Sorbonne, CNRS, and held at the Sorbonne library, December 16-18, 2015, as part of the research project "Metaphysics of Science" (ANR-12-BSH3-0009) funded by ANR.

These papers represent a significant part of the spectrum of topics covered in present-day metaphysics of science. Foundational issues concern the very possibility of metaphysics of science, the nature and epistemic status of claims made in this field, and the criteria of their justification and evaluation. Some authors (Ladyman and Ross 2007) have presented metaphysicians with a simple alternative: according to them, one possibility of pursuing metaphysics takes it to be a form of enquiry proceeding by conceptual analysis on purely a priori grounds, drawing its justifications exclusively from common sense intuitions and the analysis of ordinary language statements, and taking its concepts, theses and tools from the history of philosophy. The alternative promoted by Ladyman and Ross consists in replacing traditional metaphysics by what they call "scientific metaphysics": it takes metaphysics to be a purely a posteriori enterprise, its concepts and theses being exclusively derived from and evaluated in light of contemporary science.

The first two papers in this special issue, by Alexandre Guay and Thomas Pradeu and Amanda Bryant, challenge the simple alternative just sketched and elaborated by several authors (among others, Redhead 1995; Maudlin 2007; Esfeld 2012, 2013; French 2014). In their paper "Right Out of the Box: How to Situate Metaphysics of Science in Relation to Other Metaphysical Approaches", Guay and Pradeu first distinguish metaphysics applied to science from scientific metaphysics. The first examines how such traditional metaphysical concepts as causality, law, individual or reduction, can be enriched by contemporary science and help interpret it. The aim of the second is to elaborate a worldview that takes account of current science. However, they show that the latter leaves open a whole array of options: scientific metaphysics can be developed in realist or non-realist frameworks; it need not be based exclusively on physics but can be based on other sciences. Scientific metaphysics need not be, in Strawson's (1959) terms, "revisionary", i.e. aim at correcting the worldview of common sense, but can also be developed in a "descriptive" way. This can be done by naturalizing human conceptual structure through cognitive science. Guay and Pradeu situate metaphysics of science with respect to a whole array of conceptions of metaphysics: (1) metaphysical theses can be justified a priori or a posteriori, (2) they can be descriptive or revisionary, and (3) the justification and evaluation of metaphysical theses can rely on science, but also on common sense and/or traditional metaphysics. It would take an argument to show that the former excludes the latter.

Amanda Bryant's paper "Keep the Chickens Cooped: The Epistemic Inadequacy of Free Range Metaphysics" distinguishes two ways of conceiving metaphysics: scientific or naturalized metaphysics and what she calls "free range metaphysics". Science has only a nominal role in the latter's construction and evaluation of metaphysical theses and theories. While she argues that such non-scientific constraints on theory choice as consistency, simplicity, and intuitive plausibility are not sufficiently robust 
and fail to provide free range metaphysics with epistemic warrant, it can nevertheless be fruitful (in the sense of producing "collateral benefits"), by developing techniques for making clear statements, for suggesting hypotheses that may become integrated into science later (Popper 1993). Bryant shows that although free range metaphysics is epistemically inferior to scientific metaphysics, on count of both robustness and epistemic warrant, free range metaphysics plays a useful role by developing conceptual tools that can be used in scientific metaphysics (French and McKenzie 2012).

All other papers in the special issue make constructive contributions to metaphysics of science, either concerning science in general or specific fields of science.

Michael Esfeld's paper "A proposal for a minimalist ontology" generalizes the primitive ontology approach to quantum mechanics. He constructs a general ontological framework that allows for a realist interpretation of physical theories but that does not fall prey to the pessimistic induction, in terms of an extremely parsimonious ontology that postulates only permanent matter points individuated by changing distance relations. Where other realist interpretations of science take properties and laws of nature relating them to be part of the ontology, Esfeld argues that both properties and laws belong to the representation that science constructs in order to account in the best and simplest way for the evolution of the configuration of matter.

In his paper "Physical Modality, Laws and Counterfactuals", James Woodward elaborates a way of accounting for the metaphysical concept of modality within physics without postulating any "non-Humean entities" such as powers or dispositions. Physics makes or justifies claims about what is and is not possible for certain systems. Woodward suggests that it is possible to account for such modal claims in terms of the concepts of invariance and independence, in a framework that relies on a strict distinction, in the description and scientific explanation of facts, between laws and initial conditions.

Manuel Martinez paper "Synergic kinds" suggests an improvement on the concept of natural kinds as "homeostatic property clusters". In a similar spirit as Woodward's paper, Martinez elaborates the concept of a natural kind without positing any special "metaphysical entities", such as essences, but rather explores the conditions under which the use of natural kinds can be useful in science, as a conceptual tool for organizing the practice of scientific inference. Using conceptual tools from information science, he shows that the concept of a homeostatic property cluster is too narrow to cover all cases in which science uses natural kinds. In synergic kinds, the basis for inductive inferences is more complex than in homeostatic kinds: In synergic kinds, the presence or absence of several properties forms a non-redundant basis for inferences to other properties; whereas in cluster kinds, the property of one (sometimes but not necessarily an essential) property is sufficient as an inference base, information about other properties in the cluster being redundant.

The last two papers explore metaphysical consequences of case studies in specific sciences.

In his paper "Neural Correlates without Reduction: The Case of the Critical Period", Muhammad Ali Khalidi shows that what is presently known about the neural correlates of the cognitive phenomenon of a critical period is incompatible with various forms of reductionism and eliminativism. He shows how it is possible to evaluate metaphysical theses such as reductionism and eliminativism by paying close attention 
to the ways the different relevant sciences, i.e. psychology and ethology on one side and neuroscience on the other, construct their categories. As a thesis in metaphysics of science, reductionism claims that every theoretical category of a given "higher-level" science such as psychology or ethology corresponds to a unique category of some underlying lower-level science, such as neuroscience, in such a way that it is in principle possible to derive eventually all hypotheses about the higher-level category from hypotheses about the lower-level category. Khalidi shows, for the case of the critical period, that reduction is blocked not only because different neural mechanisms have been discovered to implement critical periods of different perceptual and cognitive capacities in different species but that one and the same neural mechanism can, in different neural and non-neural contexts, implement different cognitive phenomena. Such a "many-to-many" or "cross-cutting" relationship between neural and cognitive kinds is incompatible with reduction.

In his paper "Incubating a Future Metaphysics: Quantum Gravity", Joshua Norton argues for a strong version of scientific metaphysics, in which even the most abstract and conceptual parts of metaphysics are constrained by contemporary science, and more specifically by fundamental physics. According to contemporary physical theories of quantum gravity, such as loop quantum gravity theory and string theory, spacetime is not a fundamental aspect of reality. These theories are the last in a series of scientific theories that have influenced metaphysics. Other examples are Newtonian physics challenging Aristotle's metaphysical conception of heavenly bodies and their movements, quantum mechanics challenging Leibniz' principle of the identity of indiscernibles, and general relativity challenging Kant's doctrine of space as a form of intuition structured according to Euclidean geometry. Norton argues that the fact that spacetime, as traditionally understood, has no role in contemporary theories of quantum gravity justifies a revolution in metaphysics: It undermines all classical interpretations of the distinction between abstract and concrete. If either string theory or loop quantum gravity theory is true, none of the traditional conceptions of the distinction between mathematical and physical objects is correct.

\section{References}

Carnap, R. (1931). Die Überwindung der Metaphysik durch logische Analyse der Sprache. Erkenntnis, 2, 219-241.

Carnap, R. (1936). Testability and meaning I. Philosophy of Science, 3, 419-471.

Carnap, R. (1937). Testability and meaning II. Philosophy of Science, 4, 1-40.

Carnap, R. (1950). Empiricism, semantics, and ontology. Revue Internationale de Philosophie, 4, $20-40$.

Duhem, P. (1906/1981). La Théorie physique. Repr. Paris: Vrin.

Esfeld, M. (2012). Physique et Métaphysique: Une Introduction à La Philosophie de La Nature. Lausanne: Presses polytechniques et universitaires romandes.

Esfeld, M. (2013). Metaphysics and science. In B. Kaldis (Ed.), Encyclopedia of philosophy and the social sciences (pp. 601-604). Thousand Oaks, CA: SAGE.

French, S. (2014). The structure of the world: Metaphysics and representation. New York: Oxford University Press.

French, S., \& McKenzie, K. (2012). Thinking outside the toolbox: Towards a more productive engagement between metaphysics and philosophy of physics. European Journal of Analytic Philosophy, 8(1), 42-59.

Hacking, I. (1983). Representing and intervening. Cambridge: Cambridge University Press. 
Hahn, H., Neurath, O., \& Carnap, R. (1929). Wissenschaftliche Weltauffassung - Der Wiener Kreis. Wien: Artur Wolf Verlag.

Hempel, C. G., \& Oppenheim, P. (1948/1965). Studies in the logic of explanation. In C.G. Hempel (Ed.), Aspects of scientific explanation (pp. 245-290). Repr. New York: The Free Press.

Kuhn, T. (1962). The structure of scientific revolutions. Chicago: University of Chicago Press.

Ladyman, J., \& Ross, D. (2007). Every thing must go: Metaphysics naturalized. Oxford: Oxford University Press.

Mach, E. (1883). Die Mechanik in ihrer Entwicklung historisch-kritisch dargestellt. Leipzig: Brockhaus.

Maudlin, T. (2007). The metaphysics within physics. New York: Oxford University Press.

Maxwell, G. (1962). The ontological status of theoretical entities. In H. Feigl \& G. Maxwell (Eds.), Scientific explanation, space, and time. Minnesota studies in the philosophy of science (Vol. 3, pp. 3-15). Minneapolis: University of Minnesota Press.

Popper, K. R. (1993). Why even pseudo-sciences may well be meaningful. Metaphysical programmes for science. In K. R. Popper (Ed.), Realism and the aim of science. London: Routledge. chap. 23.

Quine, W. (1953/1980a). On what there is. In From a logical point of view. Repr, 2nd edn (pp. 1-19). Cambridge, MA: Harvard University Press.

Quine, W. (1953/1980b). Two dogmas of empiricism. In From a logical point of view. Repr, 2nd edn (pp. 20-46). Cambridge, MA: Harvard University Press.

Redhead, M. (1995). From physics to metaphysics. Cambridge: Cambridge University Press.

Strawson, P. F. (1959). Individuals. London: Methuen. 